\title{
Parenteral nutrition versus enteral nutrition in severe acute pancreatitis ${ }^{1}$
}

\author{
Nutrição parenteral versus enteral em pacientes com pancreatite aguda grave
} \author{
Moura Linhares $v$ \\ ${ }^{I}$ Fellow Master degree, Assistant Professor, Surgical Department, Federal University of Maranhao (UFMA), Brazil. \\ ${ }^{\text {II }} \mathrm{PhD}$, Associate Professor, Surgical Department, UFMA, Maranhao, Brazil.

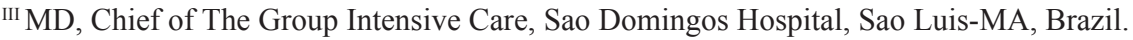 \\ ${ }^{\text {Iv }} \mathrm{PhD}$, Associate Professor, Surgical Department, Federal University of Sao Paulo (UNIFESP) Brazil. \\ ${ }^{v}$ PhD, Affiliate Professor, Surgical Department, UNIFESP, Sao Paulo, Brazil.
}

Josiel Paiva Vieira', Gutemberg Fernandes de Araújo"I, José Raimundo Araújo de Azevedo ${ }^{I I I}$, Alberto Goldenberg ${ }^{\mathrm{IV}}$, Marcelo

\begin{abstract}
Purpose: To compare the effect of parenteral versus enteral nutritional support in severe acute pancreatitis, with respect to efficacy, safety, morbidity, mortality and length of hospitalization. Methods: The study was comprised of 31 patients, divided into a parenteral group $(n=16)$ and an enteral group $(n=15)$, who met severity criteria for abdominal tomography (Balthazar classes $C$, $D$, and $E)$. The patients were compared by demographics, disease etiology, antibiotic prophylaxis, use or not of somatostatin, nutritional support, complications and disease progression. Results: There was no statistical difference in the average duration of nutritional support, somatostatin, or antibiotics in the two groups. Imipenem was the drug of choice for prophylaxis of pancreatic infections in both groups. More complications occurred in the parenteral group, although the difference was not statistically significant ( $\mathrm{p}=0.10$ ). Infectious complications, such as catheter sepsis and infections of the pancreatic tissue, were significantly more frequent in the parenteral group $(\mathrm{p}=0.006)$. There was no difference in average length of hospitalization in the two groups. There were three deaths in the parenteral group and none in the enteral group. Conclusion: Enteral nutritional support is associated with fewer septic complications compared to parenteral nutritional support.
\end{abstract}

Key words: Nutritional Support. Parenteral Nutrition. Enteral Nutrition. Pancreatitis.

\section{RESUMO}

Objetivo: Comparar o efeito do suporte nutricional parenteral versus enteral, em pancreatite aguda grave, com relação à eficácia, à segurança, à morbi-mortalidade e ao tempo de internação. Métodos: Foram estudados 31 pacientes distribuídos em grupo parenteral $(n=16)$, no período de 1995 a 1998 e grupo enteral $(n=15)$, no período de 1999 a 2002, que preencheram os critérios de gravidade pela tomografia de abdome (Balthazar C,D,E). Os pacientes foram comparados quanto aos dados demográficos, etiologia, antibioticoprofilaxia, somatostatina, suporte nutricional, complicações e evolução. Resultados: A maioria dos pacientes era Balthazar E, principalmente no grupo enteral, porém sem significado estatístico $(\mathrm{p}=0,21)$. Também não houve diferença estatística nos dois grupos em relação ao tempo médio de uso de suporte nutricional, somatostatina e antibiótico. O imipenem foi a droga de escolha para profilaxia da infecção pancreática nos dois grupos. Houve mais complicações gerais no grupo parenteral, sem significado estatístico ( $\mathrm{p}=0,10)$. As complicações infecciosas do tipo sépsis do cateter e infecção do tecido pancreático foram mais frequentes no grupo parenteral, com significância estatística $(\mathrm{p}=0,06)$. Não houve diferença na média de internação nos dois grupos. Houve três óbitos no grupo parenteral e nenhum no enteral. Conclusão: O suporte nutricional enteral está associado à menor taxa de complicações sépticas do que o parenteral. Descritores: Apoio Nutricional. Nutrição Parenteral. Nutrição Enteral. Pancreatite.

${ }^{1}$ Research performed at the Intensive Care, Sao Domingos Hospital, Sao Luis-MA, Brazil.

\section{Introduction}

Severe acute pancreatitis is found in $20-30 \%$ of patients with pancreatitis and is associated with increased risk of complications, such as multiple organ failure, necrosis, abscess and formation of pancreatic pseudocysts ${ }^{1}$. It represents a clinical challenge in intensive care, requiring prolonged hospitalization and a multidisciplinary approach, including hydro-electrolyte resuscitation, antibiotic prophylaxis, hemodynamic, respiratory, and renal support and artificial nutrition ${ }^{2}$.

This illness is associated with a systemic immunoinflammatory response that culminates with hypermetabolism and high rates of protein catabolism; consequently, nutritional reserves are rapidly consumed and 
malnutrition may appear unless a higher nutritional intake is provided $^{2}$. Thus, early nutritional support plays a central role in the management of these patients ${ }^{3}$.

Total parenteral nutritional support has long been the standard source of exogenous nutrients for these patients, however this is costly and associated with many disadvantages, including dysfunction of the intestinal mucosal barrier, which, in turn, promotes sepsis of intestinal origin ${ }^{3,4}$.

Circumventing the intestine as the route of nutrient administration contributes to loss of the mucosal barrier's integrity, exacerbating the stress and systemic inflammatory responses, aggravating the disease and potentially leading to the development of multiple organ failure, sepsis, and nosocomial infections ${ }^{5}$. Enteral nutrition, on the other hand, can maintain the integrity and function of the intestinal mucosal barrier ${ }^{6}$.

The degree of pancreatic stimulation is determined by the location in the gastrointestinal tract where food is administered ${ }^{7}$, i.e., pancreatic rest can be achieved if food is administered in the small intestine, distal to the angle of Treitz, which results in minimal or negligible stimulation of pancreatic secretion ${ }^{8}$.

Randomized clinical studies comparing parenteral vs. enteral nutrition in severe acute pancreatitis have demonstrated clear advantages of enteral nutrition. McClave et al. ${ }^{9}$ observed that enteral nutrition was equally safe and effective and significantly cheaper than total parenteral nutrition, and was also associated with faster resolution of toxicity and stress related to pancreatitis.

Kalfarentzos et al. ${ }^{6}$ demonstrated that enteral nutrition was well tolerated and was associated with fewer adverse effects or septic complications over the course of the illness, as well as with lower mortality. The cost of enteral nutrition was one-third of the cost of total parenteral nutrition.

Lower rates of sepsis, systemic inflammatory response syndrome (SIRS), and organ failure, as well as shorter hospital stays in the intensive care unit, have been reported in patients with severe acute pancreatitis on enteral vs. total parenteral nutrition ${ }^{10}$.

The objective of this study was to compare parenteral vs. enteral nutritional support in the management of patients with severe acute pancreatitis, with regards to efficacy, security, morbidity, mortality and hospitalization time.

\section{Methods}

All patients diagnosed with acute pancreatitis who were admitted to the intensive care unit of the Hospital Sao Domingos (Sao Luis-MA) between January 1995 and December 2002 were studied. The diagnosis was confirmed by elevations in levels of pancreatic enzymes (amylase and lipase), abdominal ultrasound and contrast-enhanced abdominal computerized tomographic (CT) imaging.

To stage the severity of pancreatic disease, the Balthazar tomographic classification was used ${ }^{11}$. Patients classified as Balthazar A and B and those who were transferred to other services during the course of treatment were excluded from the study.

All patients underwent a rigorous clinical treatment protocol consisting of adequate central venous fluid replacement, hemodynamic monitoring via central venous pressure (CVP), analgesia, $\mathrm{H}_{2}$-receptor blockers to prevent stress ulcers, a nasogastric tube to maintain gastric suction, prophylaxis with imipenem for pancreatic infection, inhibition of pancreatic secretions with somatostatin, parenteral or enteral nutritional support, and respiratory and renal support as needed.

Patients were evaluated for surgical treatment only when the following complications occurred: septic necrosis, abscess, infected pseudocyst and digestive fistulas. When indicated, patients were evaluated for elective open or laparoscopic cholecystectomy, after resolution of the pancreatic disease, to be performed preferably in the same hospital.

From January 1995 to June 1999, all seriously ill patients were fed via the parental route; all other patients received jejunal enteral nutrition. In this way, patients were divided into two groups according to the type of nutritional support administered.

Patients in Group A (parenteral nutrition) received a diet administered parenterally via a continuous infusion through a double-lumen polyurethane catheter placed in the superior vena cava by infra-clavicular puncture of the subclavian vein and post-procedural radiological control. This nutrition was composed of a calorie source made up of $70 \%$ carbohydrates and $30 \%$ lipids, as well as protein, supplied by a standard $10 \%$ amino acid solution, thus establishing a nitrogen/calorie ratio of $1 / 128$. Nutrition was started early (in the first $24-48$ hours after admission) and was estimated at $25-30 \mathrm{kcal} / \mathrm{kg} / \mathrm{day}$.

Patients in Group B (enteral nutrition) received a polymeric diet, administered by the enteral route, via continuous infusion through a polyurethane tube placed in the first jejunal loop and placed with the help of an endoscopist with radiographic confirmation of placement after the procedure. Feeding was started early (in the first $24-48$ hours of admission) and was estimated at $25-30 \mathrm{kcal} / \mathrm{kg} /$ day.

All patients were evaluated according to a previously established summary protocol that included data on etiology of the pancreatic disease, prophylactic antibiotic chosen, use or not of somatostatin, nutritional support, length of hospital stay, complications, disease progression, reactivation of the disease and daily nutritional cost.

The two groups were compared with respect to gender, age, etiology, severity, use of prophylactic antibiotics, use of somatostatin, general and infectious complications and disease progression to discharge or death.

Qualitative variables were grouped into proportions, and quantitative variables were expressed as means with standard deviations. Differences between qualitative variables were analyzed by the chi-squared and Fisher's exactest test where appropriate, while quantitative variables were evaluated using Student's $t$-test. The rate of rejection was defined as $<5 \%$.

\section{Results}

From January 1995 to December 2002, 48 patients diagnosed with acute pancreatitis were admitted to the intensive care unit of Sao Domingos Hospital. Fifteen were excluded for not meeting severity criteria according to the Balthazar tomographic classification, and two were transferred to other services. Ultimately, 31 cases were included in this study, of whom $19(61.2 \%)$ were males and $12(38.7 \%)$ were females. The average age was $45.0 \pm 18.0$ years. Gallstones and alcoholism were the main causes of pancreatic disease. 
Sixteen patients $(51.6 \%)$ were treated with total parenteral nutritional support (Group A), and the other 15 patients $(48.4 \%)$ with enteral nutritional support (Group B).

The prevalence of disease based on gender was similar in the two groups $(\mathrm{p}=0.886)$, and the average age in each group was $47.5 \pm 21.6$ and $44.0 \pm 14.5$ years, respectively $(p=0.604)$. Gallstones and alcoholism were the principal causes of pancreatic disease, with $12(80.0 \%)$ cases of gallstone pancreatitis and $8(50.0 \%)$ cases of alcohol-induced pancreatitis in Group A, versus $6(37 \%)$ and 2 (16.4\%), respectively, in group B $(\mathrm{p}=0.21)$.

According to the Balthazar criteria ${ }^{19}$, most patients were considered very severe ( 7 cases $(43.8 \%)$ in group A vs. $11(71.6 \%)$ in group B), with no significant difference between the groups $(\mathrm{p}=0.21)($ Table 1$)$.

TABLE 1 - Distribution of patients with acute pancreatitis in groups A and $\mathrm{B}$, based on the Balthazar tomographic classification

\begin{tabular}{ccccc}
\hline & \multicolumn{2}{c}{$\mathrm{A}$} & \multicolumn{2}{c}{$\mathrm{B}$} \\
\hline Balthazar & $\mathrm{N}$ & $\%$ & $\mathrm{~N}$ & $\%$ \\
\hline $\mathrm{C}$ & 6 & 37.5 & 2 & 14.2 \\
$\mathrm{D}$ & 3 & 18.7 & 2 & 14.2 \\
$\mathrm{E}$ & 7 & 43.8 & 11 & 71.6 \\
\hline Total & 16 & 100.0 & 15 & 100.0 \\
\hline
\end{tabular}

Chi-squared $\mathrm{p}=0.21$

There was no statistical difference in average use of nutritional support, antibiotics or somatostatin between the two groups studied $(\mathrm{p}=0.672 ; \mathrm{p}=0.062 ; \mathrm{p}=0.140$, respectively) (Table 2).

TABLE 2 - Distribution of patients with acute pancreatitis in groups A and $\mathrm{B}$, by duration of antibiotic therapy, use or not of somatostatin and nutritional route

\begin{tabular}{lcccc}
\hline Group & \multicolumn{2}{c}{ A } & \multicolumn{2}{c}{ B } \\
\hline Time (days) & Mean & SD & Mean & SD \\
\hline Antibiotic* & 15.75 & 4.67 & 15.15 & 1.77 \\
\hline Somatostatin $^{* *}$ & 5.93 & 2.64 & 7.93 & 2.89 \\
\hline Nutrition $^{* * *}$ & 13.94 & 7.68 & 17.87 & 6.66 \\
\hline
\end{tabular}

*Student's $t$-test $-p=0.672$

** Student's $t$-test $-p=0.062$

*** Student's $t$-test $-p=0.140$

Twelve (75\%, Group A) and 13 (86.7\%, Group B) patients used prophylactic antibiotics for pancreatic infection $(\mathrm{p}=0.654)$, with imipenem being the primary option for $11(91.7 \%$, Group A) and $11(84.6 \%$, Group B) patients $(\mathrm{p}=1.000)$ (Table 3).

TABLE 3 - Distribution of patients with acute pancreatitis in groups A and $\mathrm{B}$ by antibiotic used

\begin{tabular}{lcccc}
\hline Group & \multicolumn{2}{c}{$\mathrm{A}$} & \multicolumn{2}{c}{$\mathrm{B}$} \\
\hline Antibiotic & $\mathrm{N}$ & $\%$ & $\mathrm{~N}$ & $\%$ \\
\hline Imipenem & 11 & 68.8 & 11 & 73.3 \\
Ciprofloxacin & 1 & 6.2 & 1 & 6.7 \\
Ciprofloxacin+ & - & - & 1 & 6.7 \\
Metronidazole & & & & \\
Not Used & 4 & 25.0 & 2 & 13.3 \\
\hline Total & 16 & 100.0 & 15 & 100.0 \\
\hline
\end{tabular}

The majority of patients received only clinical treatment (11 (68.7\%) cases in Group A and $11(73.3 \%)$ in group B). Of the 5 cases in group A that underwent surgical intervention, 3 (18.6\%) were performed on the pancreas. In group B, interventions were performed only on the bile ducts ( 4 cases $(26.6 \%)$ ). However, there was no significant difference between the two groups $(p=0.226)$ (Table 4).

TABLE 4 - Distribution of patients with acute pancreatitis in groups A and B by surgical treatment

\begin{tabular}{lcccc}
\hline Group & \multicolumn{2}{c}{ A } & \multicolumn{2}{c}{ B } \\
\hline Surgery & $\mathrm{N}$ & $\%$ & $\mathrm{~N}$ & $\%$ \\
\hline $\begin{array}{l}\text { Laparoscopic } \\
\text { cholecystectomy }\end{array}$ & - & - & 3 & 20.0 \\
$\begin{array}{l}\text { Laparoscopic } \\
\text { cholecystectomy + } \\
\text { endoscopic papillotomy }\end{array}$ & - & - & 1 & 6.6 \\
$\begin{array}{l}\text { Conventional open } \\
\text { cholecystectomy }\end{array}$ & 1 & 6.2 & - & - \\
$\begin{array}{l}\text { Total pancreatectomy }+ \\
\text { pancreatic necrosectomy }+ \\
\text { retroperitoneal drainage }\end{array}$ & 1 & 6.2 & - & - \\
$\begin{array}{l}\text { Endoscopic papillotomy } \\
\begin{array}{l}\text { Pancreatic necrosectomy }+ \\
\text { retroperitoneal drainage }\end{array}\end{array}$ & 1 & 6.2 & - & - \\
No operation & 12.6 & - & - \\
\hline Total & 11 & 68.8 & 11 & 73.4 \\
\hline
\end{tabular}


The incidence of general complications was $11(68.7 \%)$ in group A versus $6(40 \%)$ in group B $(\mathrm{p}=0.10)$, as presented in Table 5. With regards to infectious complications, $11(68.8 \%)$ cases occurred in group A and $3(20 \%)$ in group $B(p=0.006)$. The distribution of patients with acute pancreatitis in groups $\mathrm{A}$ and $\mathrm{B}$ by type of complication are presented in Table 6 .

TABLE 5 - Distribution of patients with acute pancreatitis in groups A and $\mathrm{B}$ by presence of general complications or infections

\begin{tabular}{lccc}
\hline \multirow{4}{*}{ Complications } & & $\mathrm{A}$ & $\mathrm{B}$ \\
& & $\mathrm{N}(\%)$ & $\mathrm{N}(\%)$ \\
\hline & Yes & $11(68.8)$ & $6(40.0)$ \\
\cline { 2 - 4 } & No & $5(31.2)$ & $9(60.0)$ \\
\cline { 2 - 4 } & Total & $16(100.0)$ & $15(100.0)$ \\
\hline \multirow{3}{*}{ Infections } & & \multicolumn{2}{c}{ Chi-squared $\mathrm{p}=0.10$} \\
\cline { 2 - 4 } & Yes & $11(68.8)$ & $3(20.0)$ \\
\cline { 2 - 4 } & No & $5(31.2)$ & $12(80.0)$ \\
\hline & Total & $16(100)$ & $15(100.0)$ \\
\hline
\end{tabular}

TABLE 6 - Distribution of patients with acute pancreatitis in groups A and $\mathrm{B}$ by type of complication

\begin{tabular}{lcccc}
\hline Complication & A & $\%$ & B & $\%$ \\
\hline Catheter infection & 4 & 25.4 & 2 & 13.4 \\
Pancreatic pseudocyst & - & - & 3 & 20.0 \\
$\begin{array}{l}\text { Septic necrosis + pancreatic } \\
\text { abscess + catheter infection }\end{array}$ & 1 & 6.2 & - & - \\
$\begin{array}{l}\text { Septic necrosis + pancreatic } \\
\text { abscess }\end{array}$ & 1 & 6.2 & - & - \\
$\begin{array}{l}\text { Septic necrosis + MOFS + } \\
\text { catheter infection }\end{array}$ & 1 & 6.2 & - & - \\
$\begin{array}{l}\text { Septic necrosis + catheter } \\
\text { infection }\end{array}$ & 1 & 6.2 & - & - \\
Septic necrosis + pancreatic & 1 & 6.2 & - & - \\
abscess+ MOFS & & & & \\
Bacteremia & 1 & 6.2 & 1 & 6.6 \\
MOFS + pneumonia & 1 & 6.2 & - & - \\
\hline Without complication & 5 & 31.2 & 9 & 60.0 \\
\hline \begin{tabular}{l} 
Total \\
\hline
\end{tabular} & 16 & 100.0 & 15 & 100.0 \\
\hline
\end{tabular}

The hospitalization time was $22.25 \pm 11.07$ days in group A and $25.47 \pm 5.55$ days in group $B(p=0.320)$. The majority of patients were discharged (81.3\%); although the incidence of death was $18.75 \%$ in group A, whereas no patients died in group B $(p=0.226)$. No patients in either group required an interruption in nutritional support administration because of feeding intolerance or disease reactivation.

\section{Discussion}

In this study, patients were classified into two groups according to type of nutritional support received, and results from each group were compared. The study sample was from a single service, and patients were cared for by the same team, following the same diagnostic and therapeutic protocol throughout the study period. There was no statistical difference between the two groups based on demographic data, etiology, spectrum of severity, duration of hospitalization, or clinical or surgical treatment throughout the study period, and patients differed only in the type of nutritional support used.

From 1995 to 1999 , all patients were fed by the parenteral route, constituting $51.6 \%$ of the total cases. From 2000 to 2003 , all patients were fed through the jejunal route $(48.3 \%)$. These findings are in conformity with the history of nutritional support. Total parenteral nutrition was initially the accepted standard for the preferred route in severe acute pancreatitis ${ }^{3}$. Nonetheless, recent prospective and randomized studies have shown that providing nutrients directly to the digestive tract is much more advantageous than doing so by the parenteral route, principally because the integrity of the intestinal mucosal barrier is maintained, which is now known to be as important as allowing the pancreas to rest $^{12}$. The enteral nutritional support appears, therefore, to be an advantageous alternative route for feeding patients with severe acute pancreatitis ${ }^{8,13,14}$ and has been used more frequently in the last five years ${ }^{13}$.

The majority of patients in both groups had severe pancreatitis (Balthazar E), but there were more of these patients in the enteral group, although this was not statistically significant $(p=0.21)$ and was probably due to small sample size. Disease severity was defined by $\mathrm{CT}$ evaluation of the degree of pancreatic and peripancreatic abnormalities. Balthazar et al. ${ }^{11}$ demonstrated that only $\mathrm{CT}$ evaluation of pancreatic and peripancreatic abnormalities was sensitive enough to predict clinical outcomes. Currently, abdominal CT with intravenous contrast is the most precise test for diagnosing and staging acute pancreatitis and its complications ${ }^{11}$. Abdominal CT detects necrosis as a focal or diffuse area of reduced contrast uptake due to pancreatic parenchyma ${ }^{14}$ with a sensitivity of $87 \%$ and can detect necrosis with a sensitivity $>90 \%{ }^{11}$.

Prophylaxis for pancreatic infection was used equally in the two groups, with no statistically significant difference between them $(\mathrm{p}=0.654)$. Imipenem was the drug of choice in both groups $(p=1.00)$, and was also used for a similar length of time $(p=0.672)$. The presence of abscesses or secondary infection of the pancreatic parenchyma significantly affected both morbidity and mortality. 
Bacterial infection of necrotic pancreatic tissue occurs in approximately $40-70 \%$ of severe pancreatitis cases, and as the most serious complication is responsible for more than $80 \%$ of mortality in acute pancreatitis cases ${ }^{15}$. The microorganisms that cause pancreatic infection and sepsis in these patients are usually common Gram-negative enteric bacteria that have translocated from the intestinal lumen as a result of the loss of mucosal barrier integrity ${ }^{16}$. Clinical studies have confirmed that imipenem has excellent penetration into pancreatic tissue and broad-spectrum coverage of the bacteria that most commonly infect the pancreas. Imipenem reduces the incidence of septic complications and should therefore be used for patients with severe acute pancreatitis for a period of two weeks ${ }^{17}$.

In general, complications were more common in the parenteral group $(68.7 \%$ versus $40.0 \%)$, without a statistically significant difference $(\mathrm{p}=0.10)$; however, this may indicate a trend towards worse results in the parenteral group.

A significantly greater prevalence of catheter, pancreatic and peripancreatic tissue infections in the parenteral group was observed $(\mathrm{p}=0.006)$. Other authors have also demonstrated that total parenteral nutritional support was associated with many infectious complications such as catheter sepsis ${ }^{3}$ and sepsis of intestinal origin due to dysfunction of the intestinal mucosa barrier ${ }^{4}$. Explanations for this observation include the fact that total parenteral nutrition does not nourish the enterocyte; in addition, nutrients are largely absent in the intestinal lumen, particularly glutamine, which plays an important role in mucosal trophism ${ }^{18}$.

A previous prospective randomized study that evaluated the impact of early total parenteral nutrition in acute pancreatitis showed that the group that received early parenteral nutrition had significantly longer hospitalizations and a greater incidence of catheter sepsis, compared with a control group that received only analgesia and fluid resuscitation ${ }^{19}$.

On the other hand, enteral nutritional support is safe in patients with severe acute pancreatitis, as it is not implicated in additional stimulation of pancreatic function, nor does it impose the inconveniences of total parenteral nutrition ${ }^{6,9,10}$. Enteral nutrition has been referred to as the most physiological type of nutritional support and holds promise for improving outcomes in surgical patients, particularly after severe trauma and acute pancreatitis $^{15,20}$.

A proposed mechanism for this clinical improvement suggests that intestinal feeding maintains the integrity of the intestinal mucosal barrier against translocation of bacteria and toxins ${ }^{20}$. Moreover, in contrast to total parenteral nutrition, enteral feeding appears to modulate the acute phase response and maintain visceral protein metabolism, suggesting inhibition of the splenic cytotoxic response ${ }^{21}$.

Several controlled studies that compared enteral with parenteral nutrition in acute pancreatitis have shown that enteral jejunal feeding is well tolerated and has clear advantages over parenteral feeding, especially for reduction of septic complications, a more rapid resolution of toxicity and stress caused by the disease, greater ease of management, and cost reductions by $3-4$ fold $^{6,9}$. More recent studies have confirmed the advantages of enteral nutrition over parenteral, with respect to tolerability, safety and reduction of septic complications ${ }^{13}$.
Pancreatic surgery was performed only for complications and only in the parenteral group, although this was not statistically significant when compared with the enteral group $(p=0.226)$, due perhaps to the small sample size. However, this could indicate a trend towards greater morbidity in this patient group.

Biliary interventions were all done electively, and the majority were in the enteral group. In this group, there were no infectious complications in the pancreas, even though a greater number of patients were Balthazar class E (71.4\%). However, this result was not statistically different $(p=0.21)$. Indications for mandatory surgery for acute pancreatitis were the presence of complications such as septic necrosis or pancreatic abscess. CT-guided percutaneous drainage failed in over $40 \%$ of cases; therefore, open surgical drainage was frequently used as an initial procedure $^{22}$.

The length of hospitalization was similar in both groups, with no statistical difference between them $(p=0.320)$. This result was also found in other studies ${ }^{6,12}$. With respect to disease progression, death occurred only in the parenteral group, although this was not statistically significant $(\mathrm{p}=0.226)$. Studies have shown that the use of enteral feeding reduces length of hospital stay, morbidity and mortality, compared to total parenteral nutrition ${ }^{13}$.

The results of this study confirmed previous reports in the literature, especially those from recent years, i.e., that enteral nutrition is perfectly viable and safe for treatment of severe acute pancreatitis, free from additional pancreatic stimulation, and clearly advantageous in all aspects when compared to parenteral nutrition. However, a deficiency of this study is its retrospective nature and relatively small sample size. Therefore, studies with larger sample sizes should be done to better define the role of enteral nutritional support in the treatment of severe acute pancreatitis.

This study demonstrated that enteral nutritional support is safe and effective when compared to parenteral support. There was no difference between the groups based on general complications; however, the group that received enteral nutrition presented with fewer septic complications. There was also no difference between the groups based on mortality and length of hospitalization.

\section{Conclusion}

Enteral nutritional support is associated with fewer septic complications compared to parenteral nutritional support.

\section{References}

1. Buchler MW, Gloor B, Muller CA. Acute necrotizing pancreatitis: treatment strategy according to the status of infection. Ann Surg. 2000;232:619-26.

2. Steinberg W, Tenner S. Acute pancreatitis. N Engl J Med.1994;330:1198-210.

3. Kalfarentzos F, Karavias DD, Karatzas TM, Alevizatos BA, Androulakis JA. Total parenteral nutrition severe acute pancreatitis. J Am Coll Nutr. 1991;10:156-62.

4. Saadia R, Schein M, Macfarlane C, Boffard KD. Gut barrier function and the surgeon. Br J Surg. 1990;77(5):487-92.

5. McClave SA, Ritchie CS. Artificial nutrition in pancreatic disease: what lessons have we learned from the literature? Clin Nutr. 2000;19(1):1-6. 
6. Kalfarentzos F, Kehagias J, Mead N, Kokkinis K, Gogos CA. Enteral nutrition in severe acute pancreatitis: results of a randomized prospective trial. Br J Surg. 1997;84(12):1665-9.

7. Ragins H, Levenson SM, Singer R. Stamford W, Seifter E. Intrajejunal administration of an elemental diet at neutral $\mathrm{pH}$ avoids pancreatic stimulation. Am J Surg. 1973;126(5):606-14.

8. Corcoy R, Ma Sanchez J, Domingo P. Nutrition in the patient with severe acute pancreatitis. Nutrition. 1988;4:269-75.

9. McClave SA, Greene LM, Snider HL, Makk LJ, CheadleWG, Owens NA, Dukes LG, Goldsmith LJ. Comparison of the safety of early enteral vs parenteral nutrition in mild acute pancreatitis. JPEN J Parenter Enteral Nutr. 1997;21(1):14-20.

10. Windsor ACJ, Kanwar S, Li AGK, Barnes E, Guthrie JA, Spark JI, Welsh F, Guillou PJ, Reynolds JV. Compared with parenteral nutrition, enteral feeding attenuates the acute response and improves disease severity in acute pancreatitis. Gut. 1998;42(3):431-5.

11. Balthazar EJ, Robison DL, Megibow AJ, Ranson JHC. Acute pancreatitis: value of CT in establishing prognosis. Radiology. 1990;174:331-6.

12. McClave SA, Dryden GW. Issues of nutritional support for the patient with acute pancreatitis. Semin Gatrointest Dis. 2002;13(3):154-60.

13. Imrie CW, Carter CR, McKay CJ. Enteral and parenteral nutrition in acute pancreatitis. Best Pract Res Clin Gastroenterol. 2002;16(3):391-7.

14. Larvin M, Chalmers AG, MacMahon MJ. Dynamic contrast enhanced computed tomography: a precise technique for identifying and localising pancreatic necrosis. BMJ. 1990;300:1425-8.
15. Qamruddin AO, Chadwick PR. Preventing pancreatic infection in acute pancreatitis. J Hosp Infect. 2000;44(4):245-53.

16. Liu Q, Djuricin G, Nathan C, Gattuso P, Weinstein RA, Prinz RA. The effect of epidermal growth factor on the septic complications of acute pancreatitis. J Surg Res. 1997;69:171-7.

17. Toouli J, Booke-Smith M, Bassi C, Carr-Locke D, Telford J, Freeny P, Imrie C, Tandon R. Working Party of the Program Commitee of the Bangkok World Congress of Gastroenterology 2002. Guidelines for the management of acute pancreatitis. J Gastroenterol Hepatol. 2002;17 Suppl:S15-39.

18. Gardiner KR, Kirk SJ, Rowlands BJ. Novel substrates to maintain gut integrity. Nutr Res Rev. 1995;8(1):43-66.

19. Sax HC, Warner BW, Talamini MA,Hamilton FN, Bell RH, Fisher JE. Early total parenteral nutrition in acute pancreatitis: lack of beneficial effects. Am J Surg. 1987;153:117-24.

20. Pupelis G, Selga G, Austrums E, Kaminski A. Jejunal feeding, even when instituted late, improves outcomes in patients with severe pancreatitis and peritonitis. Nutrition. 2001;17(2):156-7.

21. Kudsk KA, Croce MA, Fabian TC, Minard G, Tolley EA, Poret HA, Kuhl MR, Brown RO. Enteral versus parenteral feeding. Effects on septic morbidity after blunt and penetrating abdominal trauma. Ann Surg. 1992;215(5):503-13.

22. Lee MJ, Ratner DW, Legemate DA. Acute complicated pancreatitis: redefining the role of interventional radiology. Radiology. 1992;183(1):171-4.

Conflict of interest: none

Financial source: none

\section{Correspondence:}

Josiel Paiva Vieira

Rua C, quadra E, casa 01, Cohaserma 2

65072-132 São Luiz - Maranhão Brasil

josielpv@hotmail.com

Received: February 22, 2010

Review: April 19, 2010

Accepted: May 18, 2010

\section{How to cite this article}

Vieira JP, Araújo GF, Azevedo JRA, Goldenberg A, Linhares MM. Parenteral nutrition versus enteral nutrition in severe acute pancreatitis. Acta Cir Bras. [serial on the Internet] 2010 Sept-Oct;25(5). Available from URL: http://www.scielo.br/acb 